\title{
Curcumin Regulates Colon Cancer by Inhibiting P-Glycoprotein in In-situ Cancerous Colon Perfusion Rat Model
}

\section{Prasad Neerati $^{1 *}$, Yakkanti A. Sudhakar ${ }^{2}$ and Jagat R Kanwar ${ }^{3}$}

${ }^{1}$ DMPK \& Clinical Pharmacology Division, Department of Pharmacology, University College of Pharmaceutical Sciences, Kakatiya University, Warangal, AP, 506009, India ${ }^{2}$ Cell signaling Laboratory, Bioscience Division, Center for Cancer and Metabolism, SRI International, Menlo PArk, CA 94025, USA

${ }^{3}$ Nanomedicine-Laboratory of Immunology and Molecular Biomedical Research (NLIMBR), School of Medicine (SoM), Molecular and Medical Research (MMR) Strategic Research Centre, Faculty of Health, Deakin University, Waurn Ponds, Geelong, Victoria 3217, Australia

\begin{abstract}
Study background: Studies on p-glycoprotein was carried out world vide with cell lines like Caco2, MDR1LLC-PK1 and MDR1-MDCK in-vitro, but most of the results were failed to produce similar results in-vivo. In the present study curcumin inhibitory action on p-glycoprotein increased permeability of irinotecan, so in the colon cancer it would be beneficial if curcumin used as add on therapy.

Methods: Intra-rectal administered of N-Nitroso N-methyl urea $(2 \mathrm{mg} / \mathrm{Kg})$ induced colon cancer. Single pass whole length of colon in-situ perfusion was carried out in rats with irinotecan to study the influence of $\mathrm{p}$-glycoprotein modulators like verapamil and curcumin. The rats were divided in to 5 groups $(n=6)$, Group I served as control perfused with $30 \mu \mathrm{g} / \mathrm{ml}$ of irinotecan, propronolol and phenol red. Group II was cancerous group, induced by $\mathrm{N}$-methyl N-nitroso urea. Group III was perfused with irinotican in cancerous rats. Group IV, perfused with irinotican in presence of verapamil and group $V$ was pre-treated with curcumin and then perfused with irinotican and was estimated by HPLC-UV to effective permeability coefficient.

Results: Our qRT-PCR and Western blot results confirmed that about 15-fold decreases in the expression of p-glycoprotein (P-gp) in curcumin treated colon cancer cells. Irinotecan was increased to $0.00066 \mathrm{~cm} / \mathrm{s}$ and about 11 -fold increase in verapamil-coperfused group, where curcumin pre-treated group irinotecan was increases $0.00006 \mathrm{~cm} / \mathrm{s}$ to $0.00042 \mathrm{~cm} / \mathrm{s}$ that is about 7 -fold increase p-glycoprotein inhibitory activity by verapamil and curcumin found to be significantly enhanced the cancerous colon permeability of irinotecan.
\end{abstract}

Conclusions: Any safe suitable p-glycoprotein inhibitors along with irinotecan will enhance the therapeutic benefit in the treatment of the colon cancer.

Keywords: Curcumin; Effective permeability; p-glycoprotein; In situ colon perfusion; RP- HPLC

\section{Introduction}

The cause of cancer is mainly because of two reasons: those with an environmental cause and those with a hereditary cause and also a leading killing disease in the world. Common environmental factors leading to cancer include: tobacco, diet, obesity, infections, radiation, lack of physical activity, and environmental pollutants [1]. These environmental factors cause or enhance abnormalities in the genetic material of cells may leads to cancer [2]. Cell reproduction is an extremely complex process that is normally tightly regulated by several classes of genes, including oncogenes and tumour suppressor genes. Hereditary or acquired abnormalities in these regulatory genes can lead to the development of cancer. Small percentage of different types of cancer, like familial adenomatous polyposis, breast cancer is entirely hereditary. Many types of cancer are caused by a series of mutations. Each mutation alters the behaviour of the cell. Cancer is fundamentally a disease of failure of regulation of tissue growth. In order for a normal cell to transform into a cancer cell, the genes which regulate cell growth and differentiation must be altered [3]. The affected genes are divided into two broad categories; oncogenes are genes which promote cell growth and reproduction. Tumour suppressor genes are genes which inhibit cell division and survival. Malignant transformation can occur through the formation of novel oncogenes, the inappropriate over-expression of normal oncogenes, or by the under-expression or disabling of tumour suppressor genes. Typically, changes in many genes are required to transform a normal cell into a cancer cell [4]. Genetic changes can occur at different levels and by different mechanisms. The gain or loss of an entire chromosome can occur through errors in mitosis. More common are mutations, which are changes in the nucleotide sequence of genomic DNA. Some environments make errors more likely to arise and propagate. Such environments can include the presence of disruptive substances called carcinogens, repeated physical injury, heat, ionising radiation, or hypoxia [5]. Chemo resistance to metastatic malignant melanoma is due to over expression of p-gp on cell membrane [6]. P-gp expression is suppressed by IL2 would help in cancer chemotherapy where the drugs are $\mathrm{p}$-gp substrates and the presence of $5^{\prime}$ translated fragment in $\mathrm{p}$-gp improves its translational efficacy $[7,8]$.

P-gp over expression is one of the reasons to develop multi drug resistance and inhibition of P-gp helps in the cancer treatment [9-11]. Invasive cancers that are confined within the wall of the colon (TNM stages I and II) are often curable with surgery, Colorectal cancer is the third most commonly diagnosed cancer in the world, but it is

*Corresponding author: Prasad Neerati, Ph.D, Assistant Professor of Pharmacy DMPK \& Clinical Pharmacology Division, Department of Pharmacology, University College of Pharmaceutical Sciences, Kakatiya University, Warangal, AP, India, Tel: 91-9494812120; Fax: 91-8702453508; E-mail: prasadneerati@gmail.com

Received June 26, 2013; Accepted July 02, 2013; Published July 08, 2013

Citation: Neerati P, Sudhakar YA, Kanwar JR (2013) Curcumin Regulates Colon Cancer by Inhibiting P-Glycoprotein in In-situ Cancerous Colon Perfusion Rat Model. J Cancer Sci Ther 5: 313-319. doi:10.4172/1948-5956.1000221

Copyright: $\odot 2013$ Neerati $P$, et al. This is an open-access article distributed under the terms of the Creative Commons Attribution License, which permits unrestricted use, distribution, and reproduction in any medium, provided the original author and source are credited. 
more common in developed countries [12]. ATP-binding cassette transporters (ABC-transporter) are members of a protein super family. $\mathrm{ABC}$ transporters are transmembrane proteins that utilize the energy of adenosine triphosphate (ATP) hydrolysis to carry out certain biological processes including translocation of various substrates across membranes and non-transport-related processes such as translation of RNA and DNA repair. They transport a wide variety of substrates across extra- and intracellular membranes, including metabolic products, lipids, sterols, and drugs. ABC transporters are involved in tumor resistance, cystic fibrosis, bacterial multidrug resistance, and a range of other inherited human diseases [13]. In vitro and animal studies have proven that curcumin has antitumor, antioxidant, antiarthritic, antiamyloid, anti-ischemic and inflammatory properties. Its potential anticancer effects stem from its ability to induce apoptosis in cancer cells without cytotoxic effects on healthy cells. Curcumin can interfere with the activity of the transcription factor NF- $\kappa B$, which has been linked to a number of inflammatory diseases such as cancer [1416]. Curcumin affected expression of metallothionein genes, tubulin genes, p53 and other genes involved in colon carcinogenesis [17]. Curcumin has multiple therapeutic activities against the diseases of the cardiovascular, loss of bone and muscle, depression and neuropathic pain [18]. The present study illustrates the P-gp inhibitory activity of curcumin using irinotecan as P-gp substrate by a novel method with in situ cancerous colonic single pass perfusion method in rats.

Irinotecan is an anticancer drug having pharmacoresistance. P-glycoprotein, an efflux transporter, is located on the apical membrane of colon epithelial cells, oriented such that P-gp substrates are secreted from the epithelial cell into the colon lumen. P-gp mediated efflux has the potential to decrease colon drug absorption. Inhibition of colon P-glycoprotein may have clinically significant effects on the cellular concentration of irinotecan. To test this hypothesis, first time these studies were conducted to examine the effects of inhibition of P-glycoprotein on the absorption of irinotecan in intrarectal administered drug ( $2 \mathrm{mg} / \mathrm{Kg} \mathrm{N}$-Nitroso $\mathrm{N}$-methyl urea) induced perfusion cancerous rat model.

\section{Materials and Methods}

\section{Materials}

Irinotecan Hydrochloride, verapamil Hydrochloride, propranolol and curcumin purchased from Sigma Aldrich, Bangalore, India. Phenol Red was purchased from Himedia, Mumbai, India. Methanol, orthophosphoricacid and phosphate buffer saline purchased from Merck Chemicals, Mumbai, India.

\section{Methods}

Gene expression studies through qRT-PCR: TRIzol reagent (Invitrogen) was used to isolate total ribonucleic acid (RNA) from the control and treated cells. Briefly Caco- 2 cells were plated out in 6 well plates and treated with desired concentration of verapamil, irinotecan, curcumin and combination of verapamil and curcumin for 24-hrs before RNA extraction. The concentration of RNA present in the samples was determined by measuring the absorbance at $260 \mathrm{~nm}$ using Corona SH-1000 lab absorbance microplate reader. The isolated RNA was converted into cDNA using reverse transcription polymerase chain reaction (RT-PCR). The cDNA was amplified using quantitative real time polymerase chain reaction (qRT-PCR) which helps in detection of amplified DNA in real time. Annealing temperature of $65^{\circ} \mathrm{C}$ was used (Forward: GCCTGGCAGCTGGAAGACAAATAC; Reverse: ATGGCCAAAATCAAGGGTTAGC) and the cycle was set for 60 repeats. The qRT-PCR reaction mixture $(7.5 \mu \mathrm{l} \mathrm{SYBR}$ green premix (Bio Rad), $0.4 \mu \mathrm{l}$ forward primer, $0.4 \mu \mathrm{l}$ reverse primer, $1 \mu \mathrm{l}$ cDNA template per sample and RNase free water to make the volume of reaction mixture up to $15 \mu \mathrm{l}$ ) was prepared in standard Bio Rad PCR plates and incubated in iQ5 optical system software for quantitative expression analysis. The $2^{\wedge} \wedge$ ct values were calculated using actin as the control and the graph was plotted with these values. The amplified DNA was run on an agarose gel for further analysis of the gene expression.

Western blotting: Western blotting was performed for checking the regulation of P-gp markers. Briefly cell lysate samples after treatment were loaded onto an $8 \%$ sodium dodecyl sulphate polyacrylamide gel (SDS-PAGE) in the concentration of $120 \mu \mathrm{g} / \mathrm{ml}$. After electrophoresis the proteins were transferred from the gel onto a PVDF membrane (GE Healthcare Life Sciences). The membrane was first activated by incubating it in methanol for 2-min, then washed with Milli-Q for 10 -min and finally was allowed to soak in transfer buffer. The mini transblot (Bio Rad) sandwich assembly was used for transferring the gel. The gels were washed in the transfer buffer and then transferred using a Bio Rad tank at 100V for 1-hr. 45 min (P-gp).

Post transfer the membranes were washed with 1X TBS, 3 times for 5 -min each and then incubated in $2 \%$ skim milk as the blocking solution for 1 hour. The membranes were washed again in 1X TBS thrice and then incubated in primary antibody that was diluted in the ratio of 1:250 for one hour at room temperature (mouse monoclonal MDR-1 from Santa Cruz, sc-55510). After this the membranes were washed 3 times with 1X TBST and 2 times with $1 \mathrm{X}$ TBS for 5 minutes each. The membranes were then incubated with secondary antibody (anti-mouse HRP, Cell Signalling, and CS7076) in the dilution concentration of 1:2500 for one hour at room temperature. After probing with secondary antibody, the membranes were washed 4 times with $1 \mathrm{X}$ TBST and 2 times with $1 \mathrm{X}$ TBS for 5-min each. The membranes were then dried and activated using ECL detection system (GE Healthcare Life Sciences) for 2-min and then viewed using a Bio Rad Chemi Doc XRS camera with the help of Quantity One software.

Animal studies: For in-situ perfusion studies, Swiss Albino rats of either sex aged seven weeks (weighing 270-350 g) are procured from the Central Animal House, after getting permission from Institutional Animal Ethical Committee (IAEC/09/UCPSc/KU/2011), Kakatiya University, Warangal. The animals were placed in polypropylene cages, 4 per cage, with free access to standard laboratory diet and water. They were kept at $25 \pm 1^{\circ} \mathrm{C}$ and $45-55 \%$ relative humidity with a 12-hrs light/ dark cycle.

Colon cancer induction in rats and intrarectal administration of drugs: Colon cancer induction in rats was done as described [19]. Briefly, twenty Swiss Albino rats of either sex aged seven weeks should be administered an intrarectal dose of $2 \mathrm{mg} / \mathrm{Kg} \mathrm{N}$-Nitroso N-methyl urea dissolved in $0.5 \mathrm{ml}$ of water three times weekly for five weeks to induce colon cancer.

Identification of Aberrant Crypt Foci in Rodents: Aberrant crypt loci (ACF) are one of the earliest putative preneoplastic, and in some cases, neoplastic lesions in human colons. These microscopic lesions identified on methylene blue-stained mucosa with a lowpower-magnification microscope and which are thought to be closely related to the earliest steps in multistage colonic tumorogenesis. ACF are microscopic flat foci of abnormally widened crypts and are considered to be one of the earliest histologically identifiable putative preneoplastic lesions in colonic mucosa. These lesions are identified on 
methylene blue-stained mucosa screened on a dissecting microscope. Several pieces of evidence indicate the preneoplastic and, in some cases, early neoplastic nature of these lesions. In a carcinogen-induced colonic tumorogenesis model, these lesions may show dysplastic morphology and precede formation of adenomas and adenocarcinoma. Immediately after bowel resection, fresh resected colonic segments were opened longitudinally, and mucosa from macroscopically normal segments were dissected from the underlying layers, spread over on a what man paper, and fixed in $10 \%$ buffered formalin solution. After 48 hrs, mucosal strips were immersed in $0.1 \%$ methylene blue solution for 5 to 10 -min and screened fewer than 40X magnification for ACF. Methylene blue-stained ACF were easily identified as flat, slightly elevated hyper chromatic lesions with widened crypt mouth. Randomly selected ACF were micro dissected with a rim of normal surrounding mucosa, paraffin embedded, and serially cut perpendicular to the surface. The dissected foci were stained with hematoxylineosin (H\&E) and evaluated for proliferative activity with an anti-proliferating cell nuclear antigen (PCNA) antibody using immunohistochemical staining. PCNA immunostaining was performed on $5 \mu \mathrm{m}$ sections. After paraffin removal with xylene, rehydration, and blockage of endogenous peroxidise activity, the slides mounted in $0.01 \mathrm{~mol} / \mathrm{L}$ sodium citrate buffer were micro waved in a Sharp microwave. Microwave was used for antigen retrieval. The nonspecific binding sites were blocked with $10 \%$ goat nonimmune serum, and the slides were incubated with a primary mouse anti- PCNA antibody PC10 at 1:50 dilution, followed by use of the avidin-biotinimmunoperoxidaze method. AEC (3-amino-9-ethylcarbazole) was used as a chromogen. The slides were counterstained with Mayer's hematoxylin. Appropriate positive (human tonsils and sub mucosal lymphoid follicles) and negative controls (use of nonimmune mouse serum) were used for evaluation of PCNA staining. PCNA nuclear immunoreactivity in crypt cells was counted separately for basal, middle, and upper third of vertically oriented crypts and expressed as labelling index, which was a percentage of positively stained nuclei out of total number of nuclei in a given crypt section. PCNA-LI staining was compared separately for basal, middle, and upper compartments of the ACF and of the normal adjacent mucosa in the same slide.

Study design: Following an overnight fasting, rats were divided into 5 groups $(n=6)$. The rats we retreated as following, and then subjected for colon in-situ perfusion method [20].

Group I: Perfusion of Irinotecan [21] $(30 \mu \mathrm{g} / \mathrm{ml})+$ Propranolol $(100 \mu \mathrm{M})+$ Phenol red $(50 \mathrm{mg} / \mathrm{L})$ in Normal Rats.

Group II: Colon Cancer Induction in Normal Rats by M.N.U (N-methyl N-nitroso urea).

Group III: Perfusion of Irinotecan $(30 \mu \mathrm{g} / \mathrm{ml}+$ Propranolol (100 $\mu \mathrm{M})+$ Phenol red $(50 \mathrm{mg} / \mathrm{L})$ in Colon Cancer Induced Rats.

Group IV: Perfusion of Irinotecan $(30 \mu \mathrm{g} / \mathrm{ml})$ +Propranolol $(100 \mu \mathrm{M})+$ Phenol red $(50 \mathrm{mg} / \mathrm{L})+$ Verapamil $(200 \mu \mathrm{M})$ in colonic cancerous rats.

Group V: Perfusion of Irinotecan $(30 \mu \mathrm{g} / \mathrm{ml})+$ Propranolol $(100$ $\mu \mathrm{M})+$ Phenol red $(50 \mathrm{mg} / \mathrm{L})$ in Curcumin pretreated Colon Cancer Induced Rats.

Rat in-situ single-pass colon perfusion: Rats were anaesthetized by an intraperitoneal injection of Thiopental Sodium $(50 \mathrm{mg} / \mathrm{kg})$ and placed on a heated pad to maintain normal body temperature $\left(37^{\circ} \mathrm{C}\right)$. A midline incision was made on the abdomen and colon segment of approximately $8-10 \mathrm{~cm}$ was isolated, using the colon-caecal junction as a proximal markers reported [22-25]. Semi-circular incisions were made at each end, both ends were annulated with PE tubing and legated using silk suture and then lumen was rinsed with saline $\left(37^{\circ} \mathrm{C}\right)$. Blank perfusion buffer was first infused for $5 \mathrm{~min}$ at a flow rate of $1 \mathrm{~mL} / \mathrm{min}$ by asyringe pump, followed by perfusion of the compounds studied at a constant flow rate of $0.2 \mathrm{~mL} / \mathrm{min}$ for 90 - min, using precalibrated perfusion pump. After cannulation, the segment was covered with isotonic saline-wet gauze $\left(37^{\circ} \mathrm{C}\right)$. The perfusate was collected every $10 \mathrm{~min}$. At the end of the perfusion, the length of the segment was measured following the last collection. The animal was sacrificed by injecting saturated solution of $\mathrm{KCl}(10 \%)$. Samples were stored at $-80^{\circ} \mathrm{C}$ until analysis and perfusate concentrations of irinotecan were quantified using HPLC.

Stability studies: The stability of Irinotecan and propranolol were tested by their incubation in the perfusion solution containing Phosphate Buffer Saline ( $\mathrm{pH}-7.4)$ and phenol red at room temperature for $6 \mathrm{hrs}$ as reported [26]. Samples were taken at 1, 2, 4 and 6-hrs. Then the samples were analysed by RP-HPLC.Drugs were found to be stable in perfusion samples for 6-hrs at room temperature. The samples were stored at $-80^{\circ} \mathrm{C}$ for short-term stability experiment. There was no sign of degradation of drugs and no sign of interaction of drugs with phenol red.

Analytical methods: The schimadzu High Performance liquid Chromatography unit was equipped with: Solvent delivery module: LC-20AD, detector: SPD-20AUV-Visible Spectrophotometer, data processor: Class LC-10, Injection Port: Rheodyne (with 20 micro litre capacity loop), Column: Merck C-18 column of $25 \mathrm{~cm}$ length and $4.6 \mathrm{~mm}$ internal diameter packed with porous silica spheres of $5 \mu$ diameter. Perfusate samples from perfusion experiments were analysed using, Reversed Phase HPLC (for irinotecan and propranolol) and colorimetry is used for phenol red estimation.

Phenol red assay: The phenol red in phosphate buffer $\mathrm{pH}$ (7.4) has a characteristic red colour that was measured calorimetrically at $560 \mathrm{~nm}$. Phenol red was used as a non-absorbable marker in in-situ technique [27]. Phenol red concentration in the outlet perfusate was used to assess the steady-state condition in in-situ perfusion technique. It is also used to indicate the intestinal mucosa integrity during perfusion.

Irinotecan hydrochloride assay: Irinotecan was detected at 380 $\mathrm{nm}$, and the mobile phase used is $35 \%$ Acetonitrile: $65 \% \mathrm{KH}_{2} \mathrm{PO}_{4}$ buffer pumped at a flow rate of $1 \mathrm{ml} / \mathrm{min}$ and pressure is maintained with 100 $\mathrm{kg} . \mathrm{f} / \mathrm{cm}{ }^{2}$ The sample volume injected was $20 \mu \mathrm{l}$.

Propranolol assay: Propronolol was detected at $227 \mathrm{~nm}$, and the mobile phase used is Methanol 55\%: 45\% $0.05 \mathrm{mM} \mathrm{KH}_{2} \mathrm{PO}_{4}$ (pH -6.0) pumped at a flow rate of $1 \mathrm{ml} / \mathrm{min}$ and pressure is maintained with $130 \mathrm{~kg} . \mathrm{f} / \mathrm{cm}^{2}$. The sample volume injected was $20 \mu \mathrm{l}$. Propranolol was used as a passive, highly permeable marker $\&$ as an indicator of major changes in mesenteric blood flow [28].

\section{Data analysis by phenol red water flux correction:}

$\mathrm{C}_{\text {out }}$ (corr) was calculated from the following equation [21]

$\mathrm{C}_{\text {out (corr) }}=\mathrm{C}_{\text {out }} \times[$ Concentration of Phenol red in (CPR in) $]$ [Concentration of Phenol red out (CPR out)]

Where,

$\mathrm{C}_{\text {out (corr) }}$-corrected outlet concentration of the drug 
$\mathrm{C}_{\text {out }}$-outlet concentration of the drug

$\mathrm{CPR}_{\text {in }}$ - concentration of phenol red entering the colon Segment

$\mathrm{CPR}_{\text {out }}$ - concentration of phenol red exiting the colon Segment

Effective permeability coefficient ( $P$ eff): It is the quantitative estimate of the rate of passage of a solute across a membrane. It is calculated from the steady state concentration of compounds in the collected perfusate that is considered to be attainable when the concentration level of Phenol red is stable. The steady state effective permeability is calculated using the following equation as the buffer solution is perfused from an entrance in one end of the colon segment to an exit at the other end of the colon segment.

$\mathrm{P}_{\text {eff }}=-\mathrm{Q} \log \left[\mathrm{C}_{\text {out (corr) }} / \mathrm{C}_{\text {in }}\right]$

$2 \Pi r L$

Where,

$\mathrm{P}_{\text {eff }}=$ Effective permeability coefficient

$\mathrm{Q}=$ Perfusion flow rate

$\mathrm{C}_{\text {out }}=$ Corrected outlet drug concentration.

$\mathrm{C}_{\text {in }}=$ Inlet drug concentration

$\mathrm{r}=$ Radius of small colon

$1=$ Length of perfused colon segment

\section{Statistical analysis}

Difference in permeability results and difference between the concentration time profiles over the entire range tested were analysed by two-way ANOVA (Bonferoni post-test). The differences were considered to be significant at $\mathrm{P}<0.05$. Using graph pad prism version 5.0 performed statistical analyses.

\section{Results}

Verapamil in combination with curcumin inhibits the expression of p-gp in Caco-2 cells

We observed a significant inhibition of p-gp expression $(\mathrm{P}<0.001)$ in verapamil and curcumin treated Caco-2 cells (Figure 1A). Interestingly the expression of $\mathrm{p}$-gp was increased in the irinotecan treated caco-2 cells. There was a synergistic inhibition of $\mathrm{p}$-gp expression $(\mathrm{P}<0.001)$ observed in the combination treatments of verapamil and curcumin. This inhibition was further confirmed in Western blot (Figure 1B). Histological studies on the normal rat colon section reviled that aberrant crypt foci formation that confirms the induction of cancer in the rats with methyl -N-Nitroso urea treated group (Figures 2B \& 2C).

\section{Permeability diffrences of irinotecan in normal and cancerous rat colon}

Colon permeability of irinotecan was determined in rat colon segment using in-situ singlepass perfusion technique and the samples were analyzed by RP-HPLC method. Effective permeability values were calculated from the steady-state concentrations of compounds in the perfusate collected from the outlet. Steady-state was confirmed by the ratio of the inlet to outlet concentrations (corrected for water transport) versus time. Permeability coefficient diffrences of irinotecan in normal colon of a rat in comparision to the cancerous colon is because of increased cell count, due to which p-gp count is increased because of which it is going to result in the decreased permeability coefficient of

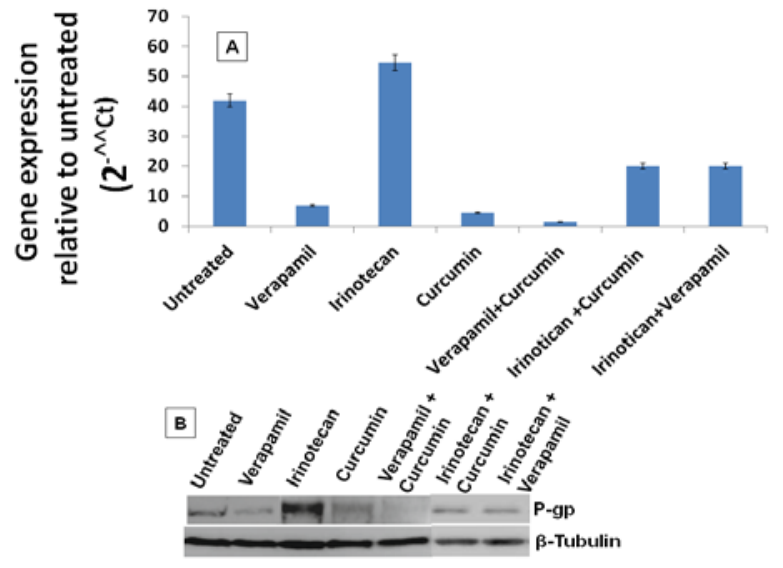

Figure 1: Verapamil in combination with curcumin inhibits the expression of p-gp in Caco-2 cells. (A) qRT-PCR and (B) Western blot showing the expression of $p-g p$ in the treated and untreated samples with verapamil, irinotecan, curcumin and combination of verapamil and curcumin.

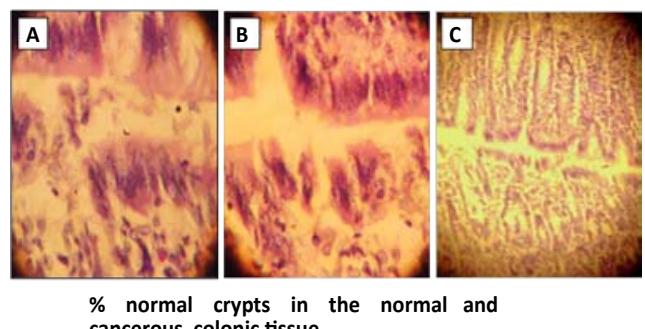
cancerous colonic tissue

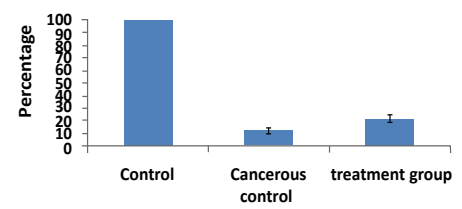

Figure 2: Histopathology of colon cancer induced in rats. Panel (A \& B). Treated groups of cancerous colon showing aberrant crypt foci formation. Panel (C).Normal colon cancer showing aberrant crypt foci formation after the treatment (that were shown as normal pathology). This is the representative histopathology from a field of $100 \mathrm{X}$ magnification. All animals in the respective group showed similar histopathology with no variations and experiments were repeated three times.

Irinotecan due to increased efflux through p-gp in cancerous colon in comparision to normal colon (Figure 3).

\section{Effect of verapamil on colon permeability of irinotecan}

Colon permeability of irinotecan was determined in rat colon segment using in-situ singlepass perfusion technique and the samples were analyzed by RP-HPLC method. Effective permeability values were calculated from the steady-state concentrations of compounds in the perfusate collected from the outlet. Steady-state was confirmed by the ratio of the inlet to outlet concentrations (corrected for water transport) versus time. The effective permeability values of irinotecan and propranolol in the absence and presence of verapamil a P-gp inhibitor.

Colon permeability coefficient of Irinotecan in the absence and presence of verapamil was found to be $0.00006 \mathrm{~cm} / \mathrm{s}$ and $0.00066 \mathrm{~cm} / \mathrm{s}$, respectively. Verapamil $(200 \mu \mathrm{M})$, a P-gp inhibitor, co-perfused with 
Irinotecan $(30 \mu \mathrm{M})$ resulted in significant increase in colon permeability by 11 -fold from $(0.00006$ to $0.00066 \mathrm{~cm} / \mathrm{sec})$. Colon permeability coefficient of Irinotecan in the absence and presence of Curcumin was found to be $0.00006 \mathrm{~cm} / \mathrm{s}$ and $0.00042 \mathrm{~cm} / \mathrm{s}$, respectively. Curcumin $(50 \mathrm{mg} / \mathrm{kg}$ ) pretreatment for a period of one week through per oral route resulted in the significant increase in the colon permeability by 7- fold. Colon permeability coefficient of propranolol in the absence and presence of verapamil was found to be $0.000079 \mathrm{~cm} / \mathrm{s}$ and 0.000087 $\mathrm{cm} / \mathrm{s}$, respectively, which was found to be statistically insignificant. Colon permeability coefficient of propranolol in the absence and presence of Curcumin was found to be $0.000079 \mathrm{~cm} / \mathrm{s}$ and 0.000085 $\mathrm{cm} / \mathrm{s}$, respectively, which was found to be statistically insignificant. Propranolol is highly permeable marker was shown to have no interaction with P-gp (Figure 4).

\section{Discussion}

Irinotecan belonging to the class II drug according to the BCS classification is having very low solubility and high permeability. Although the drug is having high permeability, in the cancerous conditions, there is going to be huge increase in the cell count because of which the P-gp count is also going to get increased, due to which the permeability of the drug will be reduced and do not have greater therapeutic benefit.

Colon permeability for a variety of drugs obtained from in situ single pass colon perfusion experiments have shown excellent correlation with human perfusion studies $[29,30]$. Also, in situ colon permeability of irinotecan were well correlated with corresponding human results

\section{Comparision of $\mathbf{P}_{\text {eff }}$ in the colon of normal and cancerous rats}

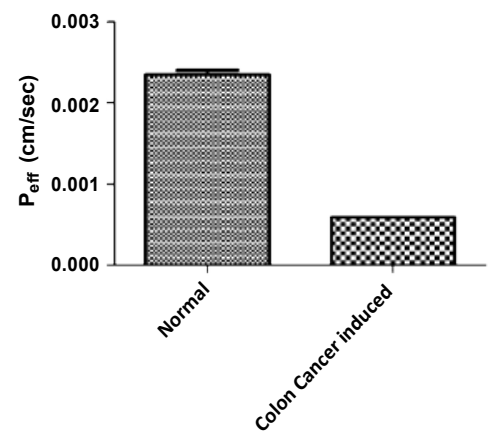

Figure 3: Comparison of $\mathrm{P}_{\text {eff }}$ in the colon of normal and intrarectal administred (2 mg/Kg N-Nitroso N-methyl urea) induced cancerous rats.

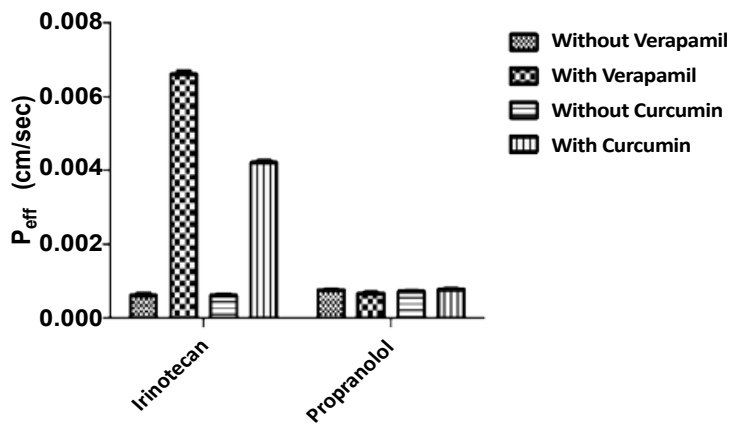

Figure 4: Comparison of $\mathrm{P}_{\text {eff }}$ of various treated groups *** Indicates $\mathrm{P}<0.005$. in terms of whether these drugs being actively absorbed or they are subject to simple passive diffusion [31]. In addition, permeability parameters obtained from in situ colon perfusion model provided a better prediction of human absorption than the cell based assays [32].

Although drug-drug interactions of irinotecan with verapamil have already been described earlier using Caco- 2 cells model and in vivo in rats [33]. Here we have applied improved in-situ model that allowed us to determine the colon permeability of the parent drug.

The colon permeability is the propensity of a compound to move across the epithelial barrier of the colon. In-vitro and in-situ absorption models, such as in situ perfusion of rat colon, Caco-2 cell monolayer model, MDCK cell lines and excised colon segments in the using chamber, are commonly used to investigate transport mechanism. Classify permeability and to predict the in-vivo absorption of drugs in humans [34]. Among the various models, cell-based assays using Caco-2 and MDCK cell lines are commonly utilized for assessing the colon permeability of compounds. However, these cell lines are mostly used to predict passive absorption and the results obtained are greatly affected by experimental parameters such as $\mathrm{pH}$ and co-solvents [35]. In contrast, in-situ approaches provide experimental conditions closer to what is encountered following oral administration, with a lower sensitivity to $\mathrm{pH}$ variations due to a preserved microclimate above the epithelial cells [36]. FDA recognized the in situ single pass colon perfusion technique as a useful model to classify a compound's absorption characteristics in the BCS [37]. These techniques maintain an intact blood supply to the colon, and can be used to estimate the impact of clearance pathways, such as enzymes and transporters, that are present in the gut. In addition, it was reported that oral drug absorption in rats and humans is very similar [38]. Thus, it is likely that the colon perfusion conducted in rats may give a better prediction of the fraction of oral dose absorbed in humans than in in-vitro models.

In the present study, in-situ single pass colon perfusion was performed in colon segment of rats to investigate the functional role of P-gp in colon permeability of irinotecan. Effective permeability of irinotecan $(30 \mu \mathrm{g} / \mathrm{ml})$ was significantly increased by co-perfusion with verapamil $(200 \mu \mathrm{M})$. It has been previously reported that verapamil is a $\mathrm{P}$-gp inhibitor and improves the colon permeability of paclitaxol (P-gp substrate) by blocking the P-gp mediated efflux [28]. Thus the increase in irinotecan colon permeability with verapamil is attributable to the P-gp modulating ability of verapamil. These results were indicated that, P-gp limits the colon permeability of irinotecan by extruding it back to the colon. Phenol red was used as a non-absorbable marker in in-situ technique [39]. Phenol red concentration in the outlet perfusate was used to assess the steady-state condition in in-situ perfusion technique.

Curcumin is responsible for the reversal of resistance by the suppression of P-gp expression [40]. Curcumin mimics are potent MDR reversal activity by inhibiting drug efflux function of P-gp, and few of them were moderately potent for efficient cancer chemotherapy [41]. Curcumin is also beneficial in a genetic mouse model of cholangiopathy and biliary fibrosis [42]. Curcuminoids as modulators extended the MDR reversing capacity those were purified from curcumin used concomitantly in conventional chemotherapy [39]. P-glycoprotein inhibitors results in increased bioavailability of P-gp drug substrates there by increasing the therapeutic benefit [43]. There is the evidence of in-vivo evidence of ABCG2-mediated efflux inhibition by curcumin with non-toxic concentrations where drug absorption is mediated by ABCG2 [44]. P-gp is a major cause of the efflux of drugs; the various effects of inhibitors of this protein in the form of 
nanomedicine are useful in treatment of various types of cancer [45]. There is the evidence of in-vivo evidence of ABCG2-mediated efflux inhibition by curcumin with non-toxic concentrations where drug absorption is mediated by ABCG2 [46]. Curcumin a non-steroidal anti-inflammatory drug (NSAID) acts as chemosensitizer in order to reverse in vitro MDR by inhibiting P-gp, and proved as potential sensitizer in anti-cancer chemotherapy [47]. It is also used to indicate the colon mucosa integrity during perfusion. Propranolol was used as a passive, highly permeable marker \& as an indicator of major changes in mesenteric blood flow [28]. The permeability values of propranolol (highly permeable maker) in the absence and presence verapamil was found to be statistically insignificantly. Therefore indicating that changes in irinotecan permeability in the presence of verapamil is not due to compromise in membrane integrity.

\section{Conclusion}

In colon cancer, oral treatment with irinotecan is convenient to patients and facilitates the use of more chronic treatment regimens. In the present study, we have shown that P-gp can decrease the colon permeability of irinotecan by effluxing it back to colon. P-gp inhibitory activity of verapamil resulted in significant improvement in colon permeability of irinotecan. There is also significant improvement in the permeability of irinotecan with curcumin. The observed effect may be beneficial in a way to reduce the pharmcoresistance of irinotecan by using any safe P-gp inhibitors to improve its oral bioavailability. Clinically, concomitant oral administration of verapamil or any safe P-gp inhibitors with irinotecan in colon cancer treatment would allow dose reduction and more importantly, the risk of metabolic saturation with irinotecan could be substantially reduced because of reduced dose and lowered accumulation of drug in body. The results of this study could be utilized to evaluate different dosing strategies for irinotecan with any safe P-gp inhibitors in patients with colon cancer. The combination of anti-cancer drugs and P-gp inhibitory natural molecule formulations led to increase the drug uptake and a significant improvement of the therapeutic effect of anti-cancer drugs in resistant tumour cells as well as cancer resistance stem cells. Thus this first time reported animal perfusion method may be useful and can be applied to assess the effect of different pharmaceutical and/or natural bioactive compounds for their potential to improve the intestinal permeability and decrease the toxicity for the purpose of evaluating novel oral nano or non-nano formulations based on p-gp inhibition.

\section{Acknowledgements}

This study was supported by the grant F.36-130/2009(SR) from University Grants Commission and start-up research funds of University College of Pharmaceutical Sciences at Kakatiya University, Warangal, AP, India to PN and also partly supported by FAMRI-062558, NIH/NCI-RO1CA143128 grants to YS.

\section{References}

1. Anand P, Kunnumakkara AB, Sundaram $C$, Harikumar KB, Tharakan $S T$, et al (2008) Cancer is a preventable disease that requires major lifestyle changes. Pharm Res 25: 2097-2116.

2. Kinzler KW, Vogelstein B (2002) Introduction: The genetic basis of human cancer. (2nd, illustrated, revised Ed.) Medical Pub Division, McGraw-Hill, New York.

3. Croce CM (2008) Oncogenes and cancer. N Engl J Med 358: 502-511.

4. Knudson AG (2001) Two genetic hits (more or less) to cancer. Nat Rev Cancer 1: 157-162.

5. Nelson DA, Tan TT, Rabson AB, Anderson D, Degenhardt K, et al. (2004) Hypoxia and defective apoptosis drive genomic instability and tumorigenesis. Genes Dev 18: 2095-2107.
6. Veau C, Faivre L, Tardivel S, Soursac M, Banide H, et al. (2002) Effect of interleukin-2 on intestinal P-glycoprotein expression and functionality in mice. J Pharmacol Exp Ther 302: 742-750.

7. Gómez-Martínez A, García-Morales P, Carrato A, Castro-Galache MD, Soto $\mathrm{JL}$, et al. (2007) Post-transcriptional regulation of P-glycoprotein expression in cancer cell lines. Mol Cancer Res 5: 641-653.

8. Schadendorf D, Herfordt R, Czarnetzki BM (1995) P-glycoprotein expression in primary and metastatic malignant melanoma. $\mathrm{Br} \mathrm{J}$ Dermatol 132: 551-555.

9. Tokunaga $\mathrm{Y}$, Hosogi H, Hoppou T, Nakagami M, Tokuka A, et al. (2001) Effects of MDR1/P-glycoprotein expression on prognosis in advanced colorecta cancer after surgery. Oncol Rep 8: 815-819.

10. Linn SC, Giaccone G (1995) MDR1/P-glycoprotein expression in colorectal cancer. Eur J Cancer 31A: 1291-1294.

11. Fillpits M, Suchomel RW, Dekan G, Stiglbauer W, Haider K, et al. (1997) Expression of the multidrug resistance-associated protein (MRP) gene in colorectal carcinomas. Br J Cancer 75: 208-212.

12. Fearon ER, Vogelstein B (1990) A genetic model for colorectal tumorigenesis Cell 61: 759-767.

13. Linardi RL, Natalini CC (2006) Multi-drug resistance (MDR1) gene and P-glycoprotein influence on pharmacokinetic and pharmacodymanic of therapeutic drugs. Cienc Rural 36: 336-341.

14. Johnson SM, Gulhati P, Arrieta I, Wang X, Uchida T, et al. (2009) Curcumin inhibits proliferation of colorectal carcinoma by modulating Akt/mTOR signaling. Anticancer Res 29: 3185-3190.

15. Katewa SD, Kapahi P (2011) Role of TOR signaling in aging and related biological processes in Drosophila melanogaster. Exp Gerontol 46: 382-390.

16. Lin CL, Lin JK (2008) Curcumin: a potential cancer chemo preventive agent through suppressing NF-kBsignaling. J Cancer Mol 4: 11-16.

17. Van Erk MJ, Teuling E, Staal YC, Huybers S, Van Bladeren PJ, et al. (2004) Time- and dose-dependent effects of curcumin on gene expression in human colon cancer cells. J Carcinog 3: 8.

18. Anand P, Thomas SG, Kunnumakkara AB, Sundaram $C$, Harikumar KB, et al. (2008) Biological activities of curcumin and its analogues (Congeners) made by man and Mother Nature. Biochem Pharmacol 76: 1590-1611.

19. Narisawa T, Fukaura Y, Hasebe M, Nomura S, Oshima S, et al. (1998) Prevention of $\mathrm{N}$-methylnitrosourea-induced colon carcinogenesis in $\mathrm{F} 344$ rats by lycopene and tomato juice rich in lycopene. Jpn J Cancer Res 89: 10031008

20. Jeong E, Huimin Lin, Ming (2000) In situ single-pass perfused rat colon mode for absorption and metabolism. In: Methods in Pharmacology and Toxicology. Springer, Germany: 65-76.

21. Rabba AK, Si L, Xue K, Li M, Li G (2011) In Situ intestinal perfusion of irinotecan application to P-gp mediated drug interaction and introduction of an improved HPLC assay. J Pharm Pharm Sci 14: 138-147.

22. Zakeri-Milani $\mathrm{P}$, Valizadeh $\mathrm{H}$, Tajerzadeh $\mathrm{H}$, Azarmi $\mathrm{Y}$, Islambolchilar $\mathrm{Z}$, et al (2007) Predicting human intestinal permeability using single-pass intestinal perfusion in rat. J Pharm Pharm Sci 10: 368-379.

23. Song NN, Li QS, Liu CX (2006) Intestinal permeability of metformin using single-pass intestinal perfusion in rats. World J Gastroenterol 12: 4064-4070.

24. Zakeri-Milani $\mathrm{P}$, Valizadeh H, Tajerzadeh H, Azarmi Y, Islambolchilar Z, et al (2007) Predicting human intestinal permeability using single-pass intestinal perfusion in rat. J Pharm Pharm Sci 10: 368-379.

25. Sutton SC, Rinaldi MT, Vukovinsky KE (2001) Comparison of the gravimetric phenol red, and 14C-PEG-3350 methods to determine water absorption in the rat single-pass intestinal perfusion model. AAPS PharmSci 3: E25.

26. Sutton SC, Rinaldi MT, Vukovinsky KE (2001) Comparison of the gravimetric, phenol red, and 14C-PEG-3350 methods to determine water absorption in the rat single-pass intestinal perfusion model. AAPS PharmSci 3: E25.

27. Miller DS, Bauer B, Hartz AM (2008) Modulation of P-glycoprotein at the bloodbrain barrier: opportunities to improve central nervous system pharmacotherapy. Pharmacol Rev 60: 196-209.

28. Varma MV, Panchagnula R (2005) Enhanced oral paclitaxel absorption with 
Citation: Neerati P, Sudhakar YA, Kanwar JR (2013) Curcumin Regulates Colon Cancer by Inhibiting P-Glycoprotein in In-situ Cancerous Colon Perfusion Rat Model. J Cancer Sci Ther 5: 313-319. doi:10.4172/1948-5956.1000221

vitamin E-TPGS: effect on solubility and permeability in vitro, in situ and in vivo. Eur J Pharm Sci 25: 445-453.

29. Amidon GL, Lennernäs H, Shah VP, Crison JR (1995) A theoretical basis for a biopharmaceutic drug classification: the correlation of in vitro drug product dissolution and in vivo bioavailability. Pharm Res 12: 413-420.

30. Varma MV, Kapoor N, Sarkar M, Panchagnula R (2004) Simultaneous determination of digoxin and permeability markers in rat in situ intestinal perfusion samples by RP-HPLC. J Chromatogr B Analyt Technol Biomed Life Sci 813: 347-352.

31. Varma MV, Panchagnula R (2005) Prediction of in vivo intestinal absorption enhancement on P-glycoprotein inhibition, from rat in situ permeability. J Pharm Sci 94: 1694-1704.

32. Salphati L, Childers K, Pan L, Tsutsui K, Takahashi L (2001) Evaluation of a single-pass intestinal-perfusion method in rat for the prediction of absorption in man. J Pharm Pharmacol 53: 1007-1013.

33. Bansal T, Mishra G, Jaggi M, Khar RK, Talegaonkar S (2009) Effect of P-glycoprotein inhibitor, verapamil, on oral bioavailability and pharmacokinetics of irinotecan in rats. Eur J Pharm Sci 36: 580-590.

34. Song NN, Li QS, Liu CX (2006) Intestinal permeability of metformin using single-pass intestinal perfusion in rats. World J Gastroenterol 12: 4064-4070.

35. Suitsui S, Pan L (2001) Evaluation of single pass intestinal perfusion in rat for the predictionof absorption in man. J Pharm Pharmacol 43: 1014-1021.

36. Lü Y, Yan Y, Wang XF (2004) Antiepileptic drug-induced multidrug resistance $\mathrm{P}$-glycoprotein overexpression in astrocytes cultured from rat brains. Chin Med J (Engl) 117: 1682-1686.

37. Jeong E, Ming $H(2000)$ Insitu single pass perfused rat intestinal model for absorption and metabolism. In methods in pharmacology and toxicology. Springer, Germany: 65-76.

38. Chiou WL, Barve A (1998) Linear correlation of the fraction of oral dose absorbed of 64 drugs between humans and rats. Pharm Res 15: 1792-1795.
39. Miller DS, Bauer B, Hartz AM (2008) Modulation of P-glycoprotein at the bloodbrain barrier: opportunities to improve central nervous system pharmacotherapy. Pharmacol Rev 60: 196-209.

40. Choi BH, Kim CG, Lim Y, Shin SY, Lee YH (2008) Curcumin down-regulates the multidrug-resistance mdr1b gene by inhibiting the PI3K/Akt/NF kappa B pathway. Cancer Lett 259: 111-118.

41. Um Y, Cho S, Woo HB, Kim YK, Kim H, et al. (2008) Synthesis of curcumin mimics with multidrug resistance reversal activities. Bioorg Med Chem 16 3608-3615.

42. Baghdasaryan A, Claudel T, Kosters A, Gumhold J, Silbert D, et al. (2009) Curcumin improves sclerosing cholangitis in Mdr2-/- mice by inhibition of cholangiocyte inflammatory response and portal myofibroblast proliferation. Gut 59: 521-530.

43. Limtrakul P, Chearwae W, Shukla S, Phisalphong C, Ambudkar SV (2007) Modulation of function of three ABC drug transporters, P-glycoprotein (ABCB1) mitoxantrone resistance protein (ABCG2) and multidrug resistance protein 1 (ABCC1) by tetrahydrocurcumin, a major metabolite of curcumin. Mol Cell Biochem 296: 85-95

44. Singh DV, Godbole MM, Misra K (2013) A plausible explanation for enhanced bioavailability of P-gp substrates in presence of piperine: simulation for next generation of P-gp inhibitors. J Mol Model 19: 227-238.

45. Kanwar JR, Singh N, Kanwar RK (2011) Role of nanomedicine in reversing drug resistance mediated by ATP binding cassette transporters and P-glycoprotein in melanoma. Nanomedicine (Lond) 6: 701-714

46. Shukla S, Zaher H, Hartz A, Bauer B, Ware JA, et al. (2009) Curcumin inhibits the activity of $A B C G 2 / B C R P 1$, a multidrug resistance-linked $A B C$ drug transporter in mice. Pharm Res 26: 480-487.

47. Angelini A, lezzi M, Di Febbo C, Di llio C, Cuccurullo F, et al. (2008) Reversa of P-glycoprotein-mediated multidrug resistance in human sarcoma MES-SA Dx-5 cells by nonsteroidal anti-inflammatory drugs. Oncol Rep 20: 731-735. 